Original Research

\title{
The Psychological Capital and Anxiety Felt by Post-Market Fire Disaster Victims
}

\section{Dian Fitria, Mustikasari Mustikasari, and Ria Utami Panjaitan}

Faculty of Nursing, Universitas Indonesia, West Java, Indonesia

\begin{abstract}
Introduction: Traditional markets are a financial resource for traders. Fire disasters at the traditional markets will have a bad effect in terms of generating both financial and psychological problems. There is a lack of studies about the psychological problems experienced by traditional market fire victims. The aim of this study is to identify the correlation of psychological capital (hope, self-efficacy, resilience, and optimism) with the anxiety level among the victims of market fire disasters in Central Jakarta.
\end{abstract}

Methods: This study used a cross-sectional approach with a non-probability sampling method. This study involved 174 market fire victims from Central Jakarta. The independent variables were psychological capital, which includes hope, selfefficacy, resilience, and optimism. The dependent variable was anxiety level. The instruments used the Hope scale, the General Self Efficacy scale, The 14-item Resilience scale (RS-14), the Life Orientation Test-Revised (LOT-R) scale and the Generalized Anxiety Disorder scale. The data analysis used an Independent T-Test, Chi-Square, and multiple logistic regression prediction modeling.

Results: The more kiosks burned, the more that the informant's anxiety increased by about4.845 times after applying a control factor of self-efficacy and optimism with a Wald value of 23.146 .

Conclusion: Psychological capital (self-efficacy and optimism) have a significant correlation with anxiety in the market fire disaster victims. Good self-efficacy and optimism can reduce the level of anxiety felt. This study highlighted that psychological capital is a part of the disaster assessment as the basis for providing disaster nursing interventions.

\section{ARTICLE HISTORY}

Received: January 14, 2020

Accepted: February 06, 2020

\section{KEYWORDS}

anxiety; market fire victims; optimism; psychological capital; self-efficacy

\section{CONTACT}

\section{Dian Fitria}

\titiayu.titi@gmail.com

$\equiv$ Faculty of Nursing, Universitas Indonesia, West Java, Indonesia

Cite this as: Fitria, D., Murtikasari, M., \& Panjaitan, R, U. (2020). The Psychological Capital and Anxiety Felt by PostMarket Fire Disaster Victims. Jurnal Ners, 15(1). 1-6. doi:http://dx.doi.org/10.20473/in.v15i1.17363

\section{INTRODUCTION}

A disaster is an event that happens suddenly, creating damage, an ecological imbalance, a disrupted livelihood and worsening or even damaging people's health and the health services. A community will bear a huge burden and require external assistance (Landesman, 2014). The Centre for Research on the Epidemiology of Disaster (2016) stated that the Asian region is the area most impacted by disasters compared to other continents in the world (Guha, Hoyois, Below, 2014). The natural condition and human behavior in Indonesia has placed Indonesia at number five based on the country's most impacted by disasters (Guha, Hoyois, Below, 2014). Disasters can be either natural or non-natural. Fire events are a non-natural disaster that occurs frequently. According to Jakarta's Central Statistical Bureau, based on burnt objects in 2014, there were 1,260 fire events, and 238 among them were in public buildings. Industrial buildings and markets were included in this list. There has been a 100\% increase from 2014 to 2015 for market fires. The Indonesian Market Sellers' Union reported that in 2014, there were 100 market fires. In 2015, there were 250. Therefore, in this paper, the researcher limits the disaster of focus to only non-natural ones with a specific focus on market fires.

Market fires occur for two reasons: old and inadequate buildings and sub-standard safety and security systems (Rarasati, 2013). The impacts of fire can be divided as follows: personal impact, loss of property, and a loss of service (Davidson, Price, McCauley, Ruggiero, 2013). Sixty five percent of postdisaster trauma originates from the loss of property. Market fire victims lose their property, which reduces 
their economic functioning (Aslam \& Tariq, 2010). The disrupted economic functions give way to psychosocial impacts in the form of anxiety for not having a livelihood (Knopp, 2016).

Several research studies have proven that anxiety is the biggest problem after a disaster. Psychosocial symptoms $(66 \%)$ rank number two in terms of postdisaster problems after musculoskeletal problems (79\%) (Nijrolder, Van der Velden, Grievink, Yzermans, 2011). Anxiety counts for $30-90 \%$ of postdisaster emotional trauma (Shoaf, 2014). Unmanaged psychosocial issues such as anxiety can worsen into depression, post-traumatic stress disorder (PTSD) and homicidal tendencies. Individuals with high psychological capital will succeed in improving their post-trauma living quality (Gail, 2013).

The resilience when facing a psychological impact due to disaster is highly influenced by the initial resilience "capital" and the initial psychological conditions possessed by each individual. This is called "psychological capital". Psychological capital is an individual's positive development related to the following characteristics: self-efficacy, positive attribution (optimism) and belief in reaching their target in life (hope). When stressors appear, they are able to persevere and survive (resiliency) (Luthans, 2007). Individuals with high psychological capital will be able to improve their post-trauma living quality (Gail, 2013). Based on these explanations, this study intends to examine the correlation between psychological capital and anxiety in the market fire victims.

\section{MATERIALS AND METHODS}

This cross-sectional study encompassed 174 respondents recruited using the non-probability sampling. The respondents of this research were the victims of a market fire disaster living in a temporary relocation area who were willing to become a respondent. The researcher collected the data accompanied by the management staff of the traditional market, PD Pasar Jaya.

There were five instruments used in this study. Hope was measured using the Hope Scale questionnaire developed by Snyder and their colleagues with a reliability value of 0.897 (Snyder, Sympson, Ybasco, Babyak, Higgins, 1996). The General Self Efficacy Questionnaire with a reliability value of 0.925 was used to measure self-efficacy (Schwarzer \& Jerusalem, 1995). The assessment of the level of resilience was done using the 14-item resilience scale (RS-14) with a Cronbach's alpha value of 0.81 (Wagnild, 1993). The optimism instrument used the Life Orientation Test-Revised scale (LOT-R) with a reliability alpha of 0.878 (Scheier, Carver, Bridges, 1994). The Generalized Anxiety Disorder questionnaire was used to measure the level of the respondents' anxiety with a Croncbach's alpha score of 0.92 and a reliability value of 0.83 (Spitzer, Kroenke, Williams, Lowe, 2006). All of the

Table 1. Mean Age of the Market Fire Victims (n=174)

\begin{tabular}{llc}
\hline Variable & Mean & Standard deviation \\
\hline Age & 35.94 & 7.343 \\
\hline
\end{tabular}

Table 2. Percentage Distribution of Gender, the Frequency of Being Market Fire victims and the Number of Kiosks Burnt $(\mathrm{n}=174)$

\begin{tabular}{lcc}
\hline Variable & $\mathbf{n}$ & $\mathbf{\%}$ \\
\hline Gender & & 55.2 \\
Men & 96 & 44.8 \\
$\quad$ Women & 78 & 3.4 \\
Education & 6 & 11.5 \\
$\quad$ None & 20 & 42 \\
$\quad$ Primary & 73 & 36.2 \\
$\quad$ Junior High School & 63 & 6.9 \\
Senior High School & 12 & 38.5 \\
College & & 51.1 \\
The frequency of being market fire victims & 67 & 10.3 \\
$\quad$ Once & 89 & 52.9 \\
Twice & 18 & 36.2 \\
$\quad$ The number of kiosks burnt & & 4.6 \\
$\quad$ One Kiosk & 92 & 6.3 \\
Two Kiosks & 63 & 8 \\
Three Kiosks & 11 & \\
$\quad$ Four Kiosks & & \\
\hline
\end{tabular}

Table 3. Psychological Capital (Hope, Self-Efficacy and Optimism) of the Market Fire Victims (n=174)

\begin{tabular}{lccc}
\hline Variable & Mean & SD & 95\% CI \\
\hline Hope & 75.07 & 10.39 & $73.51-76.62$ \\
Self-Efficacy & 28.83 & 4.180 & $28.20-29.45$
\end{tabular}


instruments were translated into Bahasa Indonesian and a reliability value of 0.867 was obtained for this study.

The analysis of the research data was carried out through univariate analysis (central tendency and frequency distribution), bivariate analysis (independent $\mathrm{T}$ test and Chi-Square) and multivariate analysis (multiple logistic regression prediction modeling).

Ethical approval number 83/UN2.F12.D /HKP.02.04/2017 was sought from the Research Ethics Committee of the Faculty of Nursing, Universitas Indonesia. The data was collected through questionnaires and did not cause any harm to the respondents. The ethical requirements and respondent rights have been fulfilled throughout the research process.

\section{RESULTS}

The average age of the respondents was 35.94 years old (Table 1). Table 2 shows that the majority of respondents were male (55.2\%), with the highest education level that of junior high school (42\%). The most common response was being a market fire victim twice $(51.1 \%)$ and the number of kiosks that had burnt most commonly totaled one (53\%).

Table 3 shows the description of psychological capital in the majority of respondents with a mean score of 75.07 (SD = 10.39; 95\% CI = 73.51-76.62). Self efficacy was 28.83 (SD $=4,180 ; 95 \%$ CI $=28,20$ $29,45)$, optimism was $36.43(\mathrm{SD}=35.75-37.10)$ and having a high resilience was (47.4\%) (Table 4$)$. Table 5 describes that the majority of respondents experience moderate anxiety (66.7\%) 3 months after the fire disaster.

The characteristics of the respondents' age and gender do not have a significant correlation with a p-

Table 4. Psychological Capital (Resilience) of the Market Fire Victims ( $\mathrm{n}=174)$

\begin{tabular}{lcc}
\hline Variable & n & \% \\
\hline Resilience & & 14.4 \\
Very good & 25 & 47.7 \\
Good & 83 & 30.5 \\
Average & 53 & 6.9 \\
Poor & 12 & 0.6 \\
Very Poor & 1 & \\
\hline
\end{tabular}

Table 5. Anxiety Level of the Market Fire Victims ( $n=174)$

\begin{tabular}{lcc}
\hline Variable & n & \% \\
\hline Low & 58 & 33.3 \\
Moderate & 116 & 66.7 \\
\hline
\end{tabular}

Table 6. Correlation between Age and the Anxiety of the Market Fire Victims ( $n=174)$

\begin{tabular}{lccc}
\hline Variable & Mean & SD & p \\
\hline Age & & & \\
Anxiety (Low) & 37.43 & 8.700 & 0.058 \\
Anxiety (Moderate) & 35.20 & 6.474 & \\
\hline
\end{tabular}

Table 7. Correlation between Gender, Education, the Frequency of Being a Market Fire Victim and the Number of Kiosks Burnt ( $\mathrm{n}=174)$

\begin{tabular}{|c|c|c|c|c|c|c|c|}
\hline \multirow{3}{*}{ Independent Variable } & \multicolumn{4}{|c|}{ Dependent Variable } & \multicolumn{2}{|c|}{ Total } & \multirow{3}{*}{$\mathbf{p}$} \\
\hline & \multicolumn{2}{|c|}{ Low } & \multicolumn{2}{|c|}{ Moderate } & \multirow{2}{*}{$\mathbf{n}$} & \multirow{2}{*}{$\%$} & \\
\hline & $\mathbf{n}$ & $\%$ & $\mathbf{n}$ & $\%$ & & & \\
\hline \multicolumn{8}{|l|}{ Gender } \\
\hline Men & 28 & 29.2 & 68 & 70.8 & 96 & 55.2 & 0.196 \\
\hline Women & 30 & 38.5 & 48 & 61.5 & 78 & 44.8 & \\
\hline \multicolumn{8}{|l|}{ Education } \\
\hline None & 2 & 33.3 & 4 & 66.7 & 6 & 3.4 & \\
\hline Primary & 7 & 35 & 13 & 65 & 20 & 11.5 & 036 \\
\hline Junior High School & 30 & 41.1 & 43 & 58.9 & 73 & 42 & 0.362 \\
\hline Senior High School & 15 & 23.8 & 48 & 76.2 & 63 & 36.2 & \\
\hline College & 4 & 33.3 & 8 & 66.7 & 12 & 6.9 & \\
\hline \multicolumn{8}{|c|}{ The frequency of being a market fire victim } \\
\hline Once & 28 & 41.8 & 39 & 58.2 & 67 & 38 & \\
\hline Twice & 30 & 33.7 & 59 & 66.3 & 89 & 52 & 0.004 \\
\hline$>2$ & 0 & 0 & 18 & 100 & 18 & 10 & \\
\hline \multicolumn{8}{|c|}{ The number of kiosks burnt } \\
\hline One Kiosk & 50 & 54.3 & 42 & 42 & 92 & 55.3 & \\
\hline Two Kiosks & 3 & 4.8 & 60 & 95.2 & 63 & 36.2 & 0.000 \\
\hline Three Kiosks & 0 & 0 & 8 & 100 & 8 & 4.6 & \\
\hline Four Kiosks & 5 & 45.5 & 6 & 54.5 & 11 & 6.3 & \\
\hline
\end{tabular}


value of 0.058 (Table 6) and 0.196 (Table 7). The number of kiosks burned and the frequency of being a market fire victim have a significant relationship with anxiety ( $\mathrm{P}=0.004 ; 0.000)$ (Table 7$)$.

Table 8 shows that there is a significant correlation between self-efficacy and optimism with anxiety with a p value 0.015, 0.014. Hope and resilience do not have a significant relationship with anxiety with a p-value of 0.922 (Table 8) and 0.526 (Table 9). The more kiosks are burnt, the more that the victim's anxiety increases by 4.845 times after being controlled by self-efficacy and optimism.

\section{DISCUSSION}

The results of the research describe that age has no influence on the level of anxiety experienced by the fire market victims. This is due to the fact that age influences individual ego. However, it does not have any correlation with the anxiety experienced (Bonnet, 2007). Age does not have a correlation with psychosocial issues but it does have a correlation with the development stages (Baily, 2004). Age does not guarantee that an individual will have the ability to cope with psychological problems such as anxiety. This is because when people growing older, the ego can either grow up or not depending on the stressors encountered in their life, in the environment and related to their individual values. Age does not ensure that a person is adaptable. Each age-based life stage relates to developmental tasks that must be fulfilled.
The individual achievements that need to be fulfilled related to the developmental tasks influences the ability to solve the psychological problems present, not age.

Gender does not have a correlation with anxiety in the market fire victims. Based on previous studies, traumatic events like traditional market fires influence the ego and developmental tasks, not age. They also no relation towards their ability to solve the anxiety experienced. Gender has no influence on the anxiety experienced by individuals especially when referring to the specific cause of the natural disaster (Robbins, 2004). This research showed that gender has no relationship on a sudden traumatic event like a market fire disaster. It becomes acceptable that gender does not relate to anxiety. This is because the victims' ability to face an anxiety-inducing experience depends on the stressor that they have experienced previously, referring to the environment, developmental tasks, ego development and also religious values and their social life.

The number of burnt kiosks is a factor influencing the respondents' anxiety. The more kiosks are burnt, the more than their level of anxiety increases by about 4.845 times after being controlled by self-efficacy and optimism. Disasters and their impact are stressors for the victims. The stressors increase with the disasterseverity factor that is experienced, in addition to the disaster frequency and the scope of their losses (Math, Nirmala, Moirangthem \& Kumar (2015). Material damage and associated losses will create

Table 8. Correlation between Psychological Capital (Hope, Self-Efficacy, and Optimism) and the Anxiety of the Market Fire Victims $(\mathrm{n}=174)$

\begin{tabular}{lcccc}
\hline Anxiety & n & Mean & SD & p \\
\hline Hope & & & & \\
$\quad$ Low & 58 & 74.97 & 9.935 & 0.922 \\
$\quad$ Moderate & 116 & 75.12 & 10.615 \\
Self-Efficacy & & & \\
$\quad$ Low & 58 & 29.90 & 4.154 & \\
Moderate & 116 & 28.29 & 4.059 & 0.015 \\
Optimism & & & & \\
Low & 58 & 36.78 & 4.645 & 0.014 \\
$\quad$ Moderate & 116 & 35.72 & 4.435 & \\
\end{tabular}

Table 9. Correlation between Psychological Capital (Resilience) and the Anxiety of the Market Fire Victims $(\mathrm{n}=174)$

\begin{tabular}{|c|c|c|c|c|c|c|c|}
\hline \multirow{3}{*}{ Independent Variable } & \multicolumn{4}{|c|}{ Dependent Variable } & \multicolumn{2}{|c|}{ Total } & \multirow{3}{*}{$\mathbf{p}$} \\
\hline & \multicolumn{2}{|c|}{ Low } & \multicolumn{2}{|c|}{ Moderate } & \multirow{2}{*}{$\mathbf{n}$} & \multirow{2}{*}{$\%$} & \\
\hline & $\mathbf{n}$ & $\%$ & $\mathbf{n}$ & $\%$ & & & \\
\hline \multicolumn{8}{|l|}{ Resilience } \\
\hline Very good & 7 & 26.9 & 19 & 73.1 & 26 & 14.9 & \multirow{5}{*}{0.526} \\
\hline Good & 29 & 34.9 & 54 & 65.1 & 83 & 47.4 & \\
\hline Average & 16 & 30.2 & 37 & 69.8 & 53 & 30.3 & \\
\hline Poor & 5 & 41.7 & 7 & 58.3 & 12 & 6.85 & \\
\hline Very Poor & 1 & 100 & 0 & 0 & 1 & 0.6 & \\
\hline
\end{tabular}

Table 10. Multivariate Logistic Regression

\begin{tabular}{lcccccc}
\hline Variable & B & SE & Wald & p & Exp (B) & OR (95\% CI) \\
\hline Self-efficacy & -0.303 & 0.063 & 23.310 & 0.000 & 0.738 & $0.653-0.835$ \\
Optimism & 0.213 & 0.059 & 12.988 & 0.000 & 1.238 & $1.102-1.390$ \\
Total number of kiosks & 1.578 & 0.328 & 23.146 & 0.000 & 4.845 & $2.547-9.213$ \\
\hline
\end{tabular}


post-fire social and psychological problems. According to the research, there were three impacts as a result of the disaster; the personal impact, a loss of property and a loss of service (Davidson, Price, McCauley, Ruggiero, 2013). The amount of postdisaster material losses sustained caused $65 \%$ of the trauma (Aslam \& Tariq, 2010). When the victims lost their products in the market, this meant that they lost financial resources as well. Material loss will affect to their family, social, financial and psychological life.

There was no severe anxiety level found in the market fire victims due to the grieving of the respondents being in the third phase. The stages of grieving are divided into the three phase. First there is the shock and numbness phase and then yearning, despair and disorganization as the second phase. The third phase is re-organization and recovery. This study was conducted 30 days after a market fire disaster, so the victims therefore have an ability to cope the resulting anxiety. The respondents also passed the acute stress syndrome phase that occurs 2 - 4 weeks after a disaster (Smid, Velden, Mulders, Knipscheer, Gersons, Kleber, 2013). After 30 days post-disaster, coping mechanisms will begin to emerge, according to the existing results of postdisaster management (Kaklauskas, Amaratungga \& Haigh, 2009). Based on disaster recovery and reorganization by the management, they provide them with a new kiosk in the relocation area so then the fire victims can still receive transactions as a financial resource, which can relieve some of their anxiety.

Fire frequency and anxiety were found to have a correlation in the respondents studied. The research concluded that the disaster and its impact become a post-disaster anxiety trigger. This stressor worsens due to the factor of disaster frequency. These stressors increase with the level of disaster-severity factor that is experienced, inclusive of disaster frequency, and the scope of any losses (Math, Nirmala, Moirangthem \& Kumar (2015). People who have experienced a disaster will experience psychological trauma. This worsens when the victims have successfully rebuilt their business and suddenly encounter the market fire disaster again. Their anxiety will be more than it was previously.

Psychological capital (self-efficacy and optimism) have a significant relationship with anxiety. The respondents' self-efficacy reached $75 \%$, with another $25 \%$ needed to increase the self-efficacy value to the point where it is hoped to lower anxiety. Self-efficacy is the belief that the market fire victims possess related to their ability to successfully face a fire disaster. Therefore, the ability to find a way out by the respondents has improved through effort and reducing their negative thinking about the event. The respondents' optimism reached $72 \%$, with $28 \%$ more needed to maximize the optimism possessed which is hoped to lower the respondents' anxiety. It can be said that the respondents have the ability to carry out certain activities in order to rise up following a fire disaster (Bandura, 1997). Improving optimism can be done through the suppression of pessimism and practicing positive thinking.

The results show that there is no correlation between the psychological capital (hope, resilience) and anxiety. The current respondent is a merged survivor in a relocation area, so an adaptation response has been formed and processed within. Hope is therefore not correlated with anxiety. Hope does not have meaningful correlation with the anxiety experienced by the merged survivors (Ozag, 2006). Resilience does not have significant correlation with the anxiety experienced by the market fire victims. Resilience is not only individualistic. It is a combination of the robustness of the system, infrastructure, government, business, community, and individuals when it comes to withstanding, tolerating, absorbing and recovering (Briding, 2014). The resilience of the victim has been built by the PD Pasar Jaya as a form of management by providing infrastructure for the purpose of relocation with good compensation. The community of fire victims allows them to support, tolerate and recover alongside each other, so good resilience has been formed and processed by the community of the victim. Although they are supported by the community and PD Pasar Jaya, they still experience anxiety. This is the reason why resilience does not have a significant correlation with the anxiety experienced by the market fire victims.

\section{CONCLUSION}

Based on the results of this research, it can be concluded that there are two psychological assets with a correlation to anxiety: optimism and selfefficacy. Optimizing the respondent's positive assets can be performed by suppressing their negative feelings and practicing positive ones in order to find a way out. Hopefully, the results of this research can be used as an input for market administrators to allow them to provide health clinics for use by the traders. The Regional Disaster Management Board can coordinate with the local health office in order to establish a healthcare post for the health team, namely the role of post-disaster psychological nurse. The regional health office, together with the government, can optimize the community program through nurse mapping in community life. Therefore, market fire victims with psychosocial issues can be assisted at the community level. Further research can be performed to encourage the development of a nursing intervention based on the psychological capital.

\section{ACKNOWLEDGEMENT}

We extend our gratitude to PD Pasar Jaya, the Faculty of Nursing, Universitas Indonesia and STIKes RS Husada for their technical and related support.

\section{REFERENCES}

Aslam, N., \& Tariq, N. (2010) 'Trauma, depression, 


\section{FITRIA ET AL.}

anxiety, and stress among individuals living in earthquake affected and unaffected areas', Pakistan Journal of Psychological Research, 25(2), pp. 131-148.

Bailey, G. T. (2004) The impact of trauma on the psychosocial development in refugees according to erikson's psychosocial theory.

Bandura, A. (1997) 'Self-efficacy and health behaviour', in Cambridge handbook of psychology, health and medicine. In A. Baum. Cambridge: Cambridge University Press, pp. 160-162.

Bonnett, H. R. (2007) 'Exploring the Relationship Between Ego Development and Mental Health'.

Briding, A. J. (2014) An analysis of factors affecting long-term disaster recovery. Walden University. Available at: http://www.tandfonline.com/doi/abs/10.3846/ 1648-715X.2009.13.117-128.

Davidson, T. M. et al. (2013) 'HHS Public Access', American Journal of Community Psychology, 52(0), pp. 97-105. doi: 10.1007/s10464-013-9579-1.

Gail Eastman (2013) The Relationship Between Psychological Capital and Workplace Bullying for Nurses.

Guha-Sapir, D., Hoyois, P. and Below, R. (2015) 'Annual Disaster Statistical Review 2014: The numbers and trends', Review Literature And Arts Of The Americas, pp. 1-50. doi: $10.1093 /$ rof/rfs003.

Kaklauskas, A., Amaratunga, D. and Haigh, R. (2009) 'Knowledge model for post-disaster management', International Journal of Strategic Property Management, 13(2), pp. 117-128. doi: 10.3846/1648-715X.2009.13.117-128.

Knopp, K. A. (2016) 'Exploring the relationship of emotional intelligence with mental health status in polish unemployed persons-differences between men and women', Polish Psychological Bulletin, 47(4), pp. 436-444. doi: 10.1515/ppb2016-0051.

Landesman, L. Y. (2014) Case Studies Public Health Prepadness \& Response to Disaster. Washington DC: Jones \& Barlett Publisher.

Luthans, Y. \& A. (2007) Psychological Capital: Developing the Human Competitive Edge. Oxford University Press.

Math, S. B., Nirmala, M. C., Moirangthem, S., \& Kumar, N. C. (2015) 'Disaster management: Mental health perspective', Indian journal of psychological medicine, 37(3), pp. 261-271.

Nijrolder, I. et al. (2011) 'Symptom attribution and presentation in general practice after an extreme life event', Family Practice, 28(3), pp. 260-266. doi: 10.1093/fampra/cmq114.

Ozag, D. (2006) 'The relationship between the trust, hope, and normative and continuance commitment of merger survivors', Journal of Management Development, 25(9), pp. 870-883. doi: 10.1108/02621710610692070.

Rarasati, A. . (2013) Asesmen Risiko Kebakaran PasarPasar di Wilayah DKI Jakarta (Studi Kasus Pasar di Lingkungan P.D Pasar Jaya.

Robbins, G. (2014) 'The relationship between generalized anxiety disorder in women and hormonal imbalances, self-efficacy and lifestyle: Implications for licensed professional counselors and counselor educators.', Dissertation Abstracts International: Section B: The Sciences and Engineering, 74(8-B(E)).

Scheier, M. F., Carver, C. S. and Bridges, M. W. (1994) 'Distinguishing Optimism From Neuroticism ( and Trait Anxiety, Self-Mastery, and Self-Esteem ): A Reevaluation of the Life Orientation Test', 67(6), pp. 1063-1078.

Schwarzer, R. \& Jerusalem, M. (1995) 'General SelfEfficacy Scale (GSE)'.

Shoaf, K. (2014) 'Organizing the health sector for response to disasters', Ciência \& Saúde Coletiva, 19(9), pp. 3705-3715. doi: 10.1590/141381232014199.03722014.

Smid, G. E. et al. (2013) 'Stress sensitization following a disaster: a prospective study Stress sensitization following a disaster: a prospective study', (2012). doi: 10.1017/S0033291711002765.

Snyder, C. R. et al. (1996) 'Development and validation of the State Hope Scale.', Journal of Personality and Social Psychology, 70(2), pp. 321335. doi: 10.1037/0022-3514.70.2.321.

Spitzer, R. L. et al. (2006) 'A \{Brief\} \{Measure\} for \{Assessing\} \{Generalized\} Anxiety\} \{Disorder\}: \{The $\{\mathrm{GAD}\}-7$, Archives of Internal Medicine, 166(10), pp. 1092-1097. doi: 10.1001/archinte.166.10.1092.

Wagnild GM, Y. H. (1993) 'Development and psychometric evaluation of the Resilience Scale', Journal of Nursing Measurement, 1(2), pp. 165178. 